\section{TRANSFERENCIA DE LA IDEA URBANA DE CIUDAD-JARDÍN Y APROPIACIÓN DEL MODELO CONSTRUIDO DE LA “UNIDAD VECINAL" EN LIMA'}

Patricia Caldas Torres ${ }^{2}$

\section{Resumen}

La ciudad-jardín, considerada por gobiernos y arquitectos de Latinoamérica como expresión de progreso y modelo para políticas de vivienda social, fue una idea urbana importada de la modernidad europea como garden-suburb durante la postguerra, en un periodo de modernización y crecimiento demográfico explosivo. Lo que se transfirió fue la teoría del neighbourhood-unit y el modelo de ciudad-satélite, conocido en este continente como Unidad Vecinal. Existen estudios sobre el modelo importado, pero poco se han investigado sus cambios informales al ser adaptado al patrón de la familia extendida y a las necesidades de sus

\section{TRANSFERENCE OF THE GARDEN CITY CONCEPT AND APPROPRIATION OF THE 'NEIGHBORHOOD UNIT' MODEL IN LIMA ${ }^{1}$}

\author{
Patricia Caldas Torres ${ }^{2}$
}

\section{Abstract}

The garden city, which has been regarded by different Latin American governments and architects as the expression of progress and model for social housing policies, is an urban idea imported from the modernist European garden-suburb concept conceived during the post-war era -a period marked by modernization and explosive population growth. The adopted concept was the theory of the neighborhood-unit and the satellite city model. Though there are studies on this imported concept, there is little research on the informal changes related to the adaptation of this idea to the context of extended 
habitantes. El objetivo del artículo es evaluar estas "transformaciones de la modernidad" en Lima, entre 1950 y 2013. Se seleccionaron dos barrios como casos de estudio: UV3 y UV Matute. La hipótesis fue que era posible descubrir tácticas de los habitantes para adaptar el barrio a sus cambiantes necesidades. Los resultados muestran la confrontación entre dos formas de hacer ciudad: una estática y planificada, con algunos elementos del garden-suburb y otra dinámica y de crecimiento informal, una ciudad cotidiana que refleja procesos de apropiación. De la asociación entre ambas ha surgido la "otra modernidad", un concepto que abre nuevas perspectivas para un planeamiento urbano inclusivo, participativo y flexible.

\section{PALABRAS CLAVE: CIUDAD-JARDÍN; APROPIACIÓN INFORMAL; PATRÓN DE LA FAMILIA EXTENDIDA; “OTRA MODERNIDAD”}

Recibido: 29-07-2015

Aceptado: 16-05-2016

1 Este artículo se basa en la investigación y data empírica de 22 conjuntos de vivienda estatal de Lima obtenida a través de visitas de campo entre los años 2005 y 2013 para la tesis doctoral "Die andere Moderne" (Caldas, 2015).

2 Dr. de la HafenCity Universitaet de Hamburgo. MsC en Arquitectura, Posgrado FAUA-UNI, Universidad Nacional de Ingeniería, Lima. Profesora del Área de Diseño, FAUA-UNI, Facultad de Arquitectura, Urbanismo y Artes de la Universidad Nacional de Ingeniería. Correo electrónico: patriciact@hotmail.de. families and to the needs of inhabitants. The goal of this research is to explore this "transformation of modernity" in Lima during 1950-2013 through the analysis of two case studies: UV3 and UVMatute. The proposed hypothesis suggests that it is possible to guess the tactics used by dwellers to adapt the neighborhood to their changing needs. The results show a conflict between two city-making methods: a static and planned method, which has some garden-suburb elements; and a dynamic, informal method, which refers to an everyday and appropriated city. The relationship between these two methods has given rise to the "other modernity" concept, which offers new possibilities for the development of an inclusive, participatory and flexible urban planning.

\section{KEYWORDS: GARDEN CITY; INFORMAL APPROPRIATION; EXTENDED FAMILY; “OTHER MODERNITY".}

Received: 29-07-2015

Accepted: 16-05-2016

1 This paper is based on empiric information collected through field research in 22 public housing developments located in Lima over the 2005-2013 period. This contribution is part of the dissertation entitled "Die andere Moderne"(Caldas, 2015)

2 The author holds a PhD from the HafenCity University Hamburg and a MSc in Architecture, FAUA-UNI Postgraduate degree from the National University of Engineering, Lima. Professor of Design, FAUA-UNI, Faculty of Architecture, Urban Planning and Arts at the National University of Engineering. Email: patriciact@hotmail.de. 


\section{Introducción}

Las Unidades Vecinales (UVs) son vistas en este estudio como un laboratorio urbano por dos razones: en primer lugar, porque estos barrios son testigos de la transferencia de la teoría del neighbourhood-unit al Perú; y en segundo lugar, porque sus alteraciones a través de la construcción informal realizadas por un grupo de residentes de clase media-baja durante más de cincuenta años, reflejan variadas formas de apropiación socio-espacial del modelo construido.

En Europa la ciudad-jardín estuvo influenciada por las ideas de Howard sobre los tres imanes ("ciudad", "campo" y "ciudad-campo") para mejorar las condiciones de vida de la clase obrera en la ciudad industrial ${ }^{3}$ y alcanzó gran difusión a partir de Letchworth (1903), primera ciudad-jardín diseñada por R. Unwin y B. Parker más bien como garden suburb. Mientras en EEUU se desarrolló la teoría del neighbourhood-unit (1929); este concepto de Perry buscaba la cohesión social en áreas residenciales

3 Ver definición de ciudad jardín y del imán ciudad-campo en Howard, 1946, p. 51-57. definidas a través de la escuela primaria como elemento esencial de la comunidad ${ }^{4}$.

Según Hardoy, el modelo que llegó de Europa a Latinoamérica en la primera mitad del siglo XX como solución al problema de la vivienda social fue el de garden suburb o ciudad-dormitorio, dirigido en países europeos a sectores de clase media. El concepto se aplicó de forma fragmentaria en Latinoamérica ${ }^{5}$. Lo que se importó fue una tipología de barrio conocida como Unidad Vecinal, inicialmente dirigida a sectores de bajos ingresos, que llegó a opacar al modelo del garden-suburb. El área urbana de la ciudad capital debía crecer a partir de un modelo de ciudad orgánica influenciado por las neighbourhood-units inglesas de la posguerra ${ }^{6}$, es decir, a través de barrios residenciales conectados entre sí y dotados con áreas verdes y equipamiento urbano pero sin centros de trabajo. Hubo ejemplos tempranos de la importación de la ciudad-jardín en São Paulo (proyectos de Unwin y Parker, 1915)ㄹ, sin embargo la influencia del neighbourhood-unit en

$4 \quad$ Ward, 1992, p. 11-12.

5 Hardoy, 1992, p. 26-39. Este autor analiza también la influencia de la personalidad de Le Corbusier en la importación del urbanismo funcional a Latinoamérica.

6 En Lima, los arquitectos importaron el modelo influenciados por el libro The Great London Plan (Abercrombie y Forschaw, 1943), el cual les fue obsequiado por la embajada inglesa. Este libro plantea la reconstrucción de Londres a partir del principio del neighbourhood-unit. Ver nota en la blibliografía en Anónimo, 1944.

7 Hofer, 2010, p. 82 
políticas de vivienda apareció muchos años después en Latinoamérica ${ }^{8}$.

Hardoy encuentra la explicación de la transferencia de prácticas y teorías europeas aplicadas al planeamiento en países latinoamericanos entre 1850 y 1930 en el ingreso de dichos países al sistema económico mundial liderado por Inglaterra9. Para Castells, las ciudades latinoamericanas constituidas después del impacto de la conquista nacieron y se desarrollaron bajo el signo de la dependencia, y lo que ocurrió luego fue un desplazamiento de la supremacía ibérica a la inglesa y posteriormente a la norteamericana ${ }^{10}$. El filósofo López Soria define esta dependencia a partir de lo que él denomina "ideología omnibuladora". Se trata de un tipo de ideología irracional que nubla el pensamiento e impide la compresión de la propia realidad ${ }^{11}$. Esta ideología, que se reconoce desde la modernización de las jóvenes repúblicas, marcó la mentalidad del Estado, de la clase alta y de los arquitectos; en su esfuerzo por conducir la ciudad latinoamericana hacia el desarrollo bajo las exigencias del capitalismo, estos grupos olvidaron entender las condiciones, locales. La importación de la teoría del

8 Segre identifica en Latinoamérica 4 fases de influencia europea en el campo de la vivienda social entre fines del s. XIX y 1970. La tercera fase (1930-45) corresponde a la influencia de los CIAM, del racionalismo y de la realización de barrios modernos en Alemania, Holanda y Austria (Segre, 2005, p. 21-23).

9 Hardoy, 1992, p. 20-21.

10 Castells, 1974, p. 61-70

11 López Soria, 1980, p. 78-80. neighbourhood-unit es una prueba de ello. Se aplicó sin discusión sobre su validez en una realidad muy distinta a la europea.

\section{Lima: ciudad informal y procesos de apropiación}

Desde la disciplina de la economía, la informalidad es definida por Sassen como un conjunto de estrategias de adaptación de individuos, consumidores y productores en vista de las cambiantes condiciones económicas. Por este motivo lo informal está anclado en el sistema económico y lo formal puede ser entendido solamente en términos de su relación con lo informal ${ }^{12}$. Hernando De Soto define lo informal como un "comportamiento extra-legal", una estrategia de sobrevivencia de los pobres ante la ausencia de una política urbana que pueda satisfacer la creciente demanda de espacios de vivienda.

Lo informal se puede entender en términos de apropiación si consideramos la iniciativa de los habitantes para mejorar sus condiciones de vida.

\section{Sassen, 1994.}


Lefèbvre define la apropiación como prácticas sociales de la vida cotidiana para producir espacio. Lo cotidiano es lo vivido, lo real, en oposición a lo abstracto, lo planificado. En la ciudad cotidiana los habitantes dejan de ser consumidores pasivos para convertirse en co-productores de sus espacios de vida ${ }^{13}$. También se puede hablar de la ciudad cotidiana en términos del imaginario colectivo de sus habitantes. En el campo de la investigación urbana actualmente los imaginarios son construcciones histórico-sociales ${ }^{14}$. Los imaginarios sociales serían "aquellas representaciones colectivas que rigen los sistemas de identificación social"15.

En cuanto a los fundamentos teóricos de este estudio, no se entiende lo "informal" como un estado pre-moderno sino como la adaptación de la ciudad a las cambiantes necesidades de grupos sociales de bajos ingresos por iniciativa de los mismos. Esta definición se basa en el concepto de la "otra modernidad" planteada por el sociólogo peruano Carlos Franco para una sociedad como la peruana, que posee una ancestral tradición del mundo andino y una herencia colonial hispana. Desde su enfoque, el autor comprende la modernidad no como la importación mecánica de un proyecto cultural europeo, sino como su adaptación a las necesidades

13 Lefèbvre, 1990, p. 191-198.

14 Los imaginarios urbanos son investigables con instrumentos cuantitativos y por otro lado requieren de un análisis interpretativo. Ver Lindón, 2007.

15 Definición de Pintos, 1995, p. 8. Ver también Silva, 2006, p. 22. locales. Franco admite que, producto del acelerado proceso migratorio de los años cincuenta, en la ciudad de Lima la modernidad no sólo desafió a grupos de migrantes de los Andes sino también a individuos de ciertos sectores sociales de bajos ingresos, quienes ya vivían en la ciudad ${ }^{16}$.

En relación al fenómeno de los cambios informales de las UVs, mayormente generados por el patrón de la familia extendida, la definición de Franco cobra un significado central desde una perspectiva contemporánea. La apropiación por parte de los residentes de estos barrios satisface, junto con los diseños modernos de los arquitectos, una necesidad social y completa el sentido de esta obra estatal. El resultado de las transformaciones del modelo construido refleja la "otra modernidad".

\section{Método de investigación}

Este estudio explorativo consideró como modelos metodológicos dos trabajos: en el medio académico europeo, el estudio Die Siedlung Pessac - 40 Jahre Wohnen à Le Corbusier. Sozio-architektonische Studie sobre el barrio francés de Pessac, obra de Le Corbusier modificada por sus habitantes ${ }^{17}$. En el

$\begin{array}{ll}16 & \text { Franco, } 1990 . \\ 17 & \text { Boudon, } 1971 .\end{array}$ 
medio latinoamericano la obra El tiempo construye, que analiza las ampliaciones realizadas por los habitantes del proyecto experimental PREVI de Lima en diversos tipos de viviendas diseñadas con crecimiento progresivo por diferentes personalidades de la escena arquitectónica internacional ${ }^{18}$.

Para analizar la importación del garden-suburb se recurrió a literatura especializada y a trabajo de $\operatorname{archivo~}^{19}$. La apropiación del modelo importado se estudió en base a un trabajo empírico y a representaciones gráficas de las adiciones en 2D y 3D. Se identificaron fragmentos con mayor cantidad de cambios al interior de la UV3 y de la UV Matute para evaluar en ellos la evolución tipológica de los bloques de vivienda ${ }^{20}$ por efecto de procesos de ampliación. Se realizaron entrevistas a habitantes fundadores, familias extendidas, dirigentes sociales, habitantes nuevos y habitantes que retornaron al barrio. Para conocer sus patrones de organización en procesos de apropiación se entrevistó a otros actores sociales como párrocos de las capillas de ambas UVs y arquitectos de la municipalidad de Lima.

19 Se revisaron planos de las UVs en el Archivo del Ministerio de Fomento (Ex-Ministerio de Vivienda).

20 Sobre la evolución tipológica de la vivienda colectiva moderna en Recife/ Brasil ampliadas informalmente, consultar Silva, 2010.

\section{EL “PLAN DE LAS UNIDADES VECINALES DE LIMA" PARA SOLUCIONAR EL PROBLEMA DE VIVIENDA}

Los arquitectos que importaron la idea del gardensuburb al Perú pertenecían a una élite de la sociedad limeña. Su "Plan de las UVs para Lima" fue una visión física de la ciudad ${ }^{21}$. En su esquema no aparecen las primeras barriadas periféricas de Lima, lo que revela la intención de "limpiar" la ciudad de asentamientos informales, según ideas predominantes de esos años en Latinoamérica ${ }^{22}$; existe sólo la ciudad oficial comprendida entre sus tres polos de crecimiento (centro tradicional, puerto y antiguos balnearios) y las urbanizaciones privadas conformadas cerca de los mismos.

Mientras en Europa los programas de vivienda en masa siguieron el modelo del garden suburb, ya desde la primera guerra mundial, motivados por el proyecto moderno de una nueva sociedad sin diferencias de clase ${ }^{23}$, en Latinoamérica, específicamente en Perú, este modelo tuvo una motivación totalmente distinta. A través de siete UVs, ubicadas en los bordes de la ciudad y dirigidas a grupos de bajos ingresos, se buscaba impedir la proliferación

21 Plan publicado en El Arquitecto Peruano, septiembre de 1945.

22 La política de "limpiar" la ciudad latinoamericana de sus asentamientos informales cruzó por este continente. John Turner describe esto como una política errada de los gobiernos que demolían casas de gente pobre paradójicamente para resolver su problema de vivienda. Ver Mc Guirk, 2014, p. 67-70.

23 Peterek, 2000, p. 168-169. 
de las barriadas y delimitar el área de expansión urbana futura de la ciudad oficial, argumentando razones funcionales sobre la base de principios lecorbusianos.

El plan dividía la ciudad en una zona industrial (con fábricas preexistentes de la Av. Colonial, eje de la ciudad que conecta el puerto con el centro tradicional) y otra zona de vivienda donde se ubicaron UVs (1,000 familias, 6,000 hab.) próximas a tradicionales barrios de clase obrera; se preveían parques entre algunas UVs. Se destinaron áreas centrales que poseían tipos de vivienda de clase baja con problemas de sobrepoblación (callejones, casas de vecindad y quintas) a un "Programa de rehabilitación". Pero dicha medida de mejoramiento, que significaba aplicar el principio de "tábula rasa", no se realizó. De las siete UVs sólo se construyeron cinco. El plan reafirmó la segregación socio-espacial existente en Lima.

En la concepción del plan los arquitectos fueron pragmáticos pues consideraron las UVs como unidades urbanas residenciales subordinadas a las estructuras de organización de la ciudad existente, es decir como lugares para vivir con espacios comunales (colegios, capilla, tiendas, áreas deportivas, etc.). Sin embargo, el plan fomentó la expansión urbana de parte de urbanizadores privados que aprovecharon la especulación de los precios de terrenos próximos a las UVs generada por esta obra estatal. Como las viviendas no pudieron ser pagadas por la clase baja y la provisión estatal para el hábitat residencial de este grupo social era mínima en comparación con la enorme necesidad de vivienda, las UVs terminaron siendo habitadas por sectores de clase media-baja. Por eso, no muy lejos de ellas siguieron proliferando los asentamientos informales.

El debate sobre la validez de la Unidad Vecinal como solución a la crisis de la vivienda vino después, con el aporte del arquitecto Adolfo Córdova, quien sostenía que dicho modelo no había resuelto la enorme demanda de vivienda y que el fenómeno de la barriada era reflejo de los problemas estructurales de la sociedad peruana; pero sobre todo con la contribución del antropólogo Matos Mar, cuyo estudio sobre las barriadas de Lima dio un giro total al valor de los asentamientos informales para el desarrollo de la ciudad ${ }^{24}$.

24 Ver Matos Mar (1977) y Córdova (1957). Sobre la posición del grupo de arquitectos reunidos en torno a la revista El Arquitecto Peruano y al arquitecto Fernando Belaúnde, defensores del modelo de la Unidad Vecinal; y para las posiciones contrarias de Córdova y de Matos Mar ver Calderón, 1990. 


\section{LA UNIDAD VECINAL Y SU ADAPTACIÓN MORFOLÓGICA EN LA CIUDAD DE LIMA}

Las UVs se materializaron, en mayor o menor medida, a través de la tipología del Zeilenbausiedlung, barrio estructurado con tipos de edificio-barra. Este modelo universal, que sigue las leyes de conformación serial, encuentra su mejor expresión como paradigma de la Modernidad en el barrio alemán de Dammerstock (1928-29), modelo predecesor de las Großsiedlungen, conjuntos de vivienda de gran escala, construidos en Europa durante la posguerra ${ }^{25}$.

La introducción de esta nueva tipología de barrio en el Perú representó, desde un punto de vista actual, un rompimiento radical con toda reminiscencia al patrón morfológico de calle-manzana de la ciudad compacta hispana (figura 1). La UV3 (1945-49), primera Unidad Vecinal de Lima construida en una superficie de 30 ha y una densidad de 200 hab./ha y poco más de 1,000 viviendas en medio de terrenos agrícolas, materializa claramente esto: tiene la apariencia de una unidad independiente, sin embargo no llegó a funcionar autónomamente. Al no ser concebida como lugar de producción y estar situada a menos de treinta minutos del centro de la ciudad, sus habitantes

25 En su tesis doctoral, Peterek dedica un capítulo al análisis de Dammerstock como paradigma de la Modernidad, (Peterek, 2000, p. 128-152). continuaron utilizando los servicios y lugares de trabajo de este centro.

La estandarización, que en Europa fue símbolo de la creencia democrática para ofrecer iguales y óptimas condiciones de vida para todos ${ }^{26}$, en las UVs de Lima fue la base de una solución tipológica, ya que las células de vivienda forman a través de su carácter aditivo un edificio-barra y varios de estos edificios forman a su vez el barrio. La UV3 muestra una textura abierta, donde las distancias y el área libre entre los edificios son similares, sin embargo el modelo no fue tan abstracto y se reconoce cierta diferenciación y polaridad entre espacios posteriores de carácter privado (calles cul-de-sac con patios individuales en el (primer piso) y espacios delanteros de carácter público (jardines comunes).

Las UVs, entre ellas la UV Matute, no muestran la claridad geométrica de la UV3 pero sí una cierta relación con su entorno urbano. En esta conexión con la ciudad radica la diferencia de la Unidad Vecinal respecto a los radicales conceptos del urbanismo funcional de Le Corbusier. Debido a los insuficientes recursos estatales, los arquitectos aprovecharon las ventajas de las facilidades comunales existentes en los barrios cercanos a estas UVs para disminuir en sus proyectos la provisión de

26 Peterek, p. 151-152. 


\section{FIGURA 1. UVS Y OTROS BARRIOS ESTATALES EN LA ESTRUCTURA DE LIMA.}

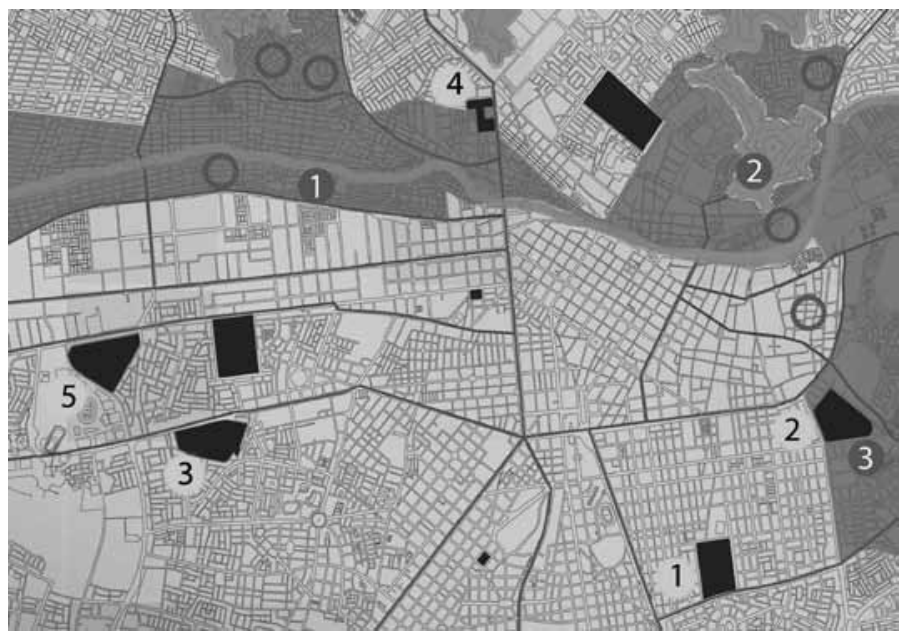

Fuente: Caldas; Kapstein, Aranda, 2015. "Lima-co-produced city", trabajo premiado en el concurso "Planetary Urbanism" organizado por la revista alemana $\mathrm{ARCH}+$

equipamiento comunal. Sólo la UV3 fue diseñada con facilidades educativas, culturales y recreativas.

En el caso de las otras UVs, la adaptación física del modelo de barrio con bloques abiertos en la morfología de Lima refleja las tensiones entre el patrón universal serial del Zeilenbausiedlung y los elementos de la tradición urbana limeña. Las UVs

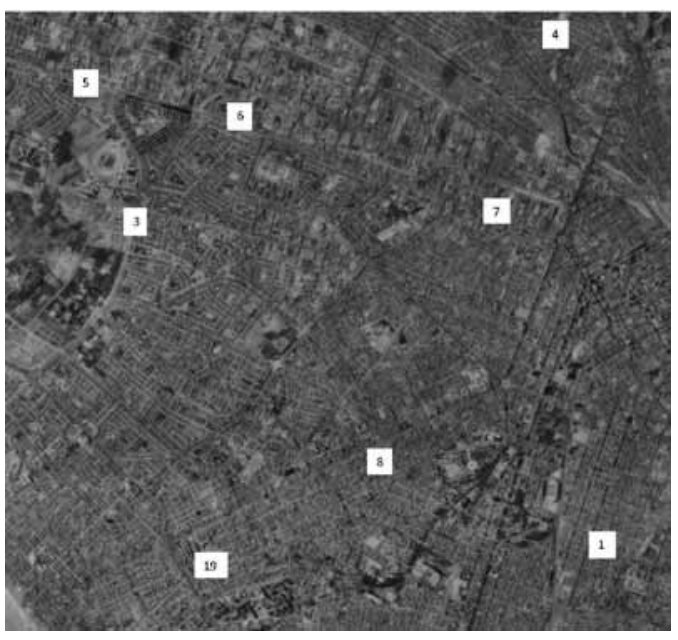

Fuente: foto aérea IGN. Lima año 1998.

construidas después de la UV3 tuvieron que ser ejecutadas en dos etapas (1953 y 1966). La primera etapa posee casas en serie y edificios-barra (con flats) que intentan cierto cerramiento pero permanecen como objetos libres en el trazado. En las casas en serie la calle permanece como elemento relevante del trazado. Y en la segunda etapa, los 
edificios-barra (con dúplex) configuran patios y calles interiores ${ }^{27}$.

\section{Selección de casos de estudio: UV3 y UV Matute}

De las cinco UVs construidas en Lima se seleccionan dos como casos de estudio, UV3 y UV Matute, pues son representativas tanto del modelo tipológico importado del Zeilenbausiedlung como de un amplio espectro de los tipos de apropiación del modelo construido.

El contexto urbano en el que se insertan ambas UVs influye en los procesos de ampliación de las viviendas. En el caso de la UV3, su cercanía a la Universidad Nacional de San Marcos (UNMSM), primera institución de este tipo en América, convierte al barrio, por iniciativa de sus residentes, en un lugar de oferta de espacios de vivienda de alquiler para una población estudiantil limeña y migrante. La zona de la UV3 próxima a la UNMSM es la que más ha cambiado debido a los nuevos

27 Después de la UV3, las otras se ejecutaron en dos o tres etapas debido a los escasos fondos del Estado. La primera etapa de estas UVs (1953-54) corresponde a los planos diseñados por el arquitecto Santiago Agurto. En tanto, la segunda etapa (1963$65)$ tuvo cambios respecto a su planteamiento original y fue diseñada por el arquitecto Enrique Ciriani. servicios que brinda la UNMSM y a su fácil accesibilidad tanto al centro de Lima como al puerto del Callao.

En el caso de la UV Matute, la primera etapa fue habitada en su mayoría por empleados de clase media y la segunda etapa por obreros y grupos de clase media-baja. Esta segunda etapa es la que muestra más cambios del espacio construido. Las transformaciones de la UV Matute tienen que ver con su inserción en un distrito tradicional de clase obrera con insuficiente provisión de facilidades comunales como es La Victoria. Sus residentes aprovecharon esta condición dada también al interior del barrio para adaptar sus viviendas a necesidades no sólo individuales sino también colectivas.

\section{Periodización de los cambios informales de las UVs, 1950- 2013}

Se ha establecido la siguiente periodización de los procesos de cambios informales:

1950-67: Inicio de los procesos de cambios informales. El surgimiento de estos procesos en las UVs 
FIGURA 2. LA UV3 (IZOUIERDA) Y LA UV MATUTE (DERECHA).
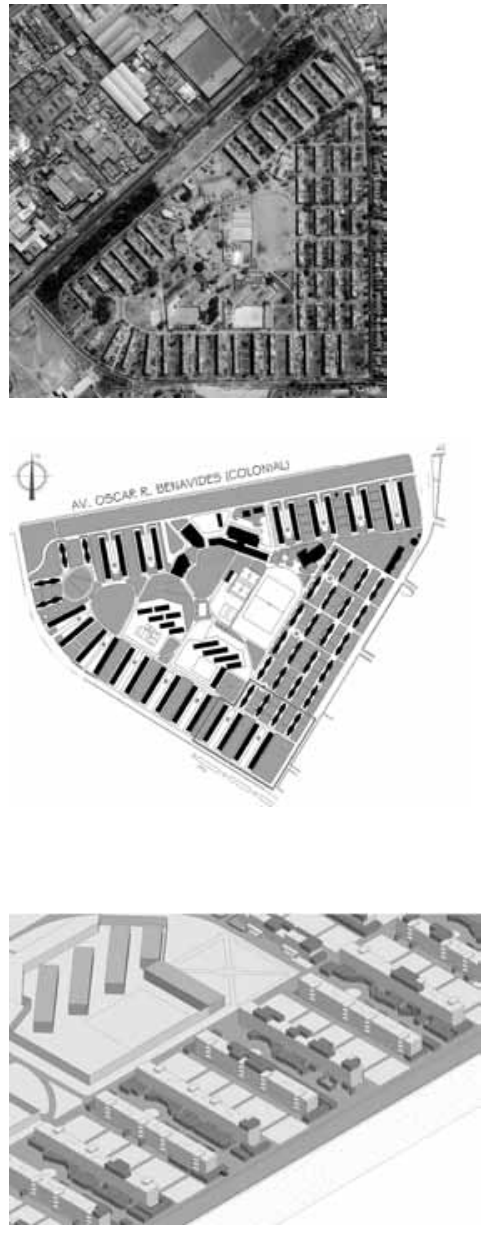

Fuente: Caldas, 2015, p. 111-114.
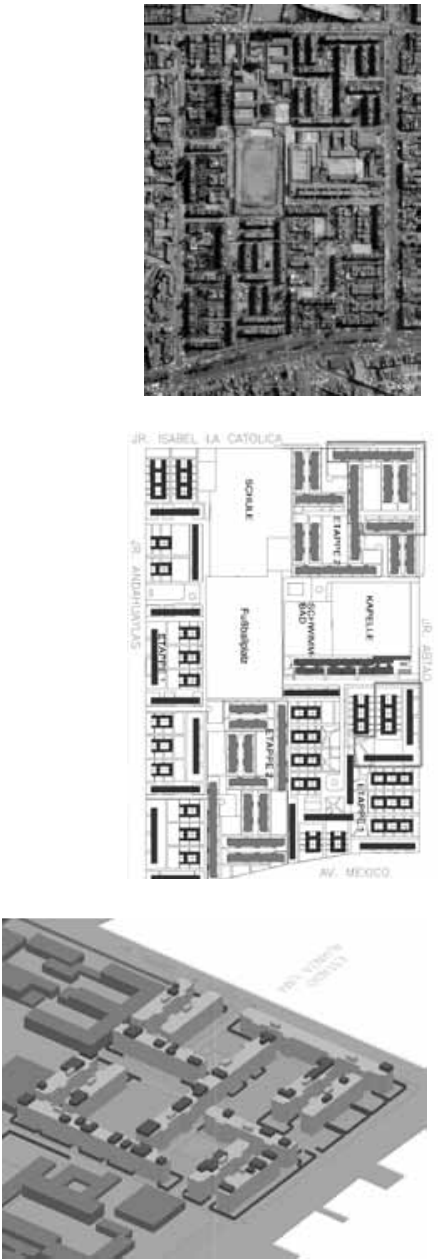

ARTÍCULO: Transferencia de la idea urbana de ciudad-jardín y apropiación del modelo construido de la "Unidad Vecinal" en Lima/Patricia Caldas Torres 
tiene relación con una fase especial en la historia de Lima iniciada en los años cuarenta, caracterizada por un explosivo crecimiento poblacional. Se trata del comienzo de la clara diferenciación de la ciudad en dos partes, la ciudad formal y la informal. Según Calderón ambas forman una unidad. La marcada presencia de asentamientos informales en la configuración urbana de Lima constituye, de manera similar a Caracas, una excepción entre otras capitales de Latinoamérica, donde lotes, generalmente sin infraestructura, son vendidos por especuladores de tierras a familias de bajos ingre$\operatorname{sos}^{28}$. En Lima, los terrenos invadidos eran propiedad del Estado o no tenían valor comercial.

En esta fase, la UV3 era prácticamente una isla en medio de áreas agrícolas. Pero este aislamiento físico, no la convirtió en ciudad-dormitorio, debido a que un gran porcentaje de los residentes fundadores adaptaron en sus viviendas espacios de producción, registrándose en 1966 una gran variedad en el uso de las salas de las viviendas destinadas para dicho fin ${ }^{29}$. Las ampliaciones de las "casas con 2 viviendas de altos sobre 2 de bajos" de la UV3, conocidas como chalets, se inician en esta primera fase en la parte posterior y años después en la parte posterior de los edificios-barra. En la UV Matute sólo existía la primera etapa del barrio. Los retiros

28 Calderón, 2005, p.14.

29 Sobre los cambios de viviendas en UV3 y UV Matute hasta 1966, ver Delgado, 1966, p. 70-71. ajardinados de las casas en serie se delimitaron con cercos por razones de seguridad.

Las ampliaciones de la UV3 surgen principalmente debido a que el $50 \%$ de los departamentos eran pequeños, con un cuarto $\left(29 \mathrm{~m}^{2}\right)$ o $1-2$ dormitorios $\left(54 \mathrm{~m}^{2}\right.$ y $\left.68 \mathrm{~m}^{2}\right)$. Esto no correspondía al alto índice de ocupación de la vivienda (7 hab./familia). La densidad inicial en 1949 fue de 200 hab./ha, cinco años después aumentó a 208 hab./ha, y diez años después a 240 hab./ha. En la UV Matute los edificios-barra (con flats) mostraban pocas transformaciones interiores debido a que el tamaño de los departamentos y número de dormitorios $\left(80 \mathrm{~m}^{2}, 3\right.$ dormitorios) eran suficientes para la familia a pesar del alto índice de ocupación de la vivienda (6 hab./familia). La densidad inicial se mantuvo en esta fase en 418 hab./ha ${ }^{30}$.

1967-1985. Mayor libertad para realizar cambios informales. La libertad que muestran los habitantes de las UVs para ampliar sus viviendas en esta fase tiene que ver con su condición de propietarios. Si bien en un inicio el Estado adoptó el sistema de departamento de alquiler, a partir de 1967 se promueve acceder a la "vivienda propia". En diez años la mayoría de los residentes se volvieron

30 lbíd., p. 46-90. 
propietarios de sus departamentos (Ley 15036). ${ }^{31}$ Hacia 1970 los cambios informales en éstos y otros barrios de Lima se volvieron frecuentes. En 1993 más de un $80 \%$ de los habitantes de las UVs eran propietarios (INEI, 199332).

En este periodo aparecen las primeras formas de crecimiento vertical de los chalets (UV3) y casas en serie (UV Matute). También se termina la segunda etapa de la UV Matute (13,29 ha. 5566 hab.) con edificios-barra que se amplían primero en la parte posterior (departamentos del primer piso) y luego, a fines de los sesenta, en los pisos superiores, en los espacios de doble altura de los dúplex. A inicios de 1980 estos edificios crecen verticalmente un piso más.

1986-2010. Consolidación de los cambios informales. Desde 1986 el Estado asume cada vez menos su rol en la provisión de vivienda social. Esto se refuerza a través de una política económica neoliberal, que por ese tiempo había empezado a orientar el desarrollo de toda Latinoamérica. Los gobiernos trasladan este rol a la población de bajos ingresos, al mercado libre y a los pobres. En las barriadas de la ciudad se consolidan los procesos de densificación por el patrón de la familia extendida.

31 Por esta ley también se traspasa la administración del equipamiento comunal de las UVs, que estaban hasta la fecha bajo el control directo de la CNV (Corporación Nacional de la Vivienda), a diversas entidades del sector público (Flores, 1967, p. 125-128).

32 Censos de población y vivienda del Instituto Nacional de Estadística del Perú (INEI).
En esta fase, la densidad de la UV3 disminuye considerablemente primero a 174hab./ha en el año 1993 y catorce años después a 133 hab./ha., sin embargo se muestra un incremento considerable de la densidad constructiva. Actualmente existe más de $30 \%$ de familias extendidas en el barrio ${ }^{33}$ y más del 20\% de viviendas con espacios de trabajo. Por otro lado, hay una disminución del índice de ocupación de la vivienda (de 7 a 4,2 hab./fam.). En la UV Matute la densidad del conjunto disminuye en el año 1993 ligeramente a 411 hab./ha y en 2007 a 378hab./ha. En la segunda etapa de la UV Matute existe más de $40 \%$ de familias extendidas; en el barrio más del 15\% de las viviendas tienen espacios de producción y el índice de ocupación de la vivienda es más bajo que el de la UV3 (3.6 hab./fam. $)^{34}$.

\section{El patrón cultural de la familia extendida en las UVs}

El crecimiento informal en las UVs refleja estrategias de adaptación de la arquitectura racional por parte de un grupo de residentes de clase media-baja que se quedó a vivir en el barrio por estar excluido

33 Información sobre el actual porcentaje de familias extendidas proporcionada por un habitante dirigente de la UV3.

34 Censos de población y vivienda en cada UV, INEI, años 1993 y 2007. 
del mercado oficial de la vivienda y por la ausencia de programas de vivienda social. La mayoría de los residentes fundadores de las UVs pertenecían a la primera generación de hijos de migrantes (70\% en la UV3 y 62\% en la UV Matute). En 1966, la UV3 contaba con $24 \%$ de familias trigeneracionales y la UV Matute con 33\% ${ }^{35}$. Las tácticas de dichos residentes, cuando al formar familia surge la necesidad de mayor espacio en la vivienda, son similares a las que existen en los procesos informales de ampliación de la barriada (figura 3). Ellos amplían la vivienda porque encuentran aquí una alternativa: accesibilidad al resto de la ciudad, cercanía a lugares de trabajo, buena infraestructura urbana, áreas verdes al interior del barrio y redes sociales.

El patrón de la familia extendida en las UVs produce lazos familiares y conexiones con el lugar. A través de este patrón, esencial en la cultura urbana de Lima, no sólo para sectores sociales de clase baja y media-baja, los habitantes identifican sus barrios como territorios de pertenencia. Este arraigo es un componente importante no sólo en las UVs, sino

35 Ver características demográficas de los residentes fundadores en la UV3 y UV Matute en Delgado, 1966. también en otros conjuntos de vivienda estatal y en los asentamientos informales de Lima ${ }^{36}$.

Se ha verificado en las UVs que en las últimas décadas el patrón de la familia extendida no necesariamente condujo a una densificación poblacional. Esto se debe a que desde 1993 se registra un crecimiento demográfico negativo en estos barrios y un cierto índice de viviendas desocupadas (6,3\% en la UV3 y 3,6\% en la UV Matute) ${ }^{37}$. Cuando queda sólo uno o dos miembros de la segunda generación, se suele vender la vivienda ampliada a nuevos habitantes de clase media, alquilar las habitaciones desocupadas o adaptarlas como espacio de trabajo.

36 Sobre la importancia de identificar territorios de pertenencia ver Lindón, 2007, p. 92.

37 Censos INEI, 1993 y 2007. 
FIGURA 3. CRECIMIENTO DE LA VIVIENDA POR EL PATRÓN DE LA FAMILIA EXTENDIDA: UV3 Y UV MATUTE.

1949

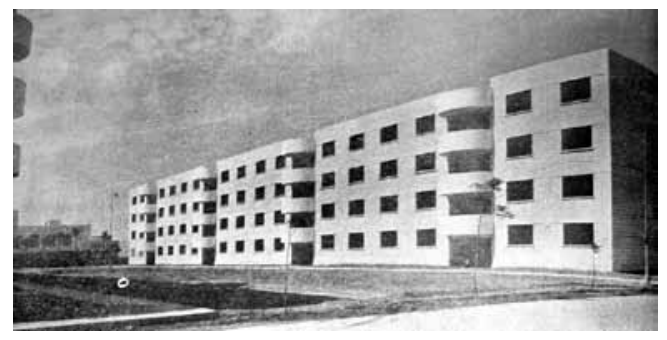

\section{5}

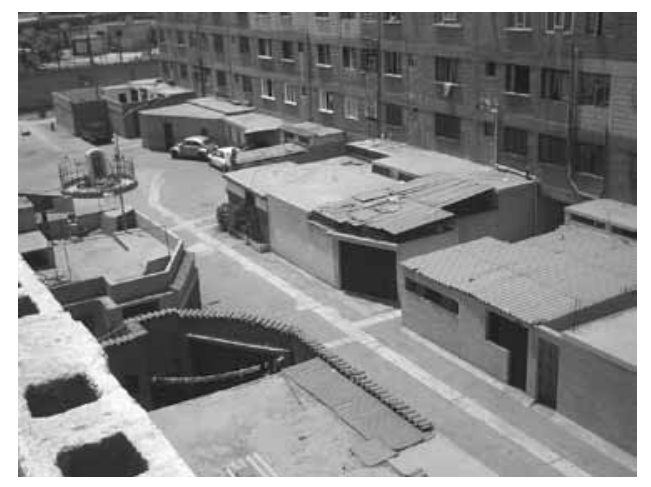

1949

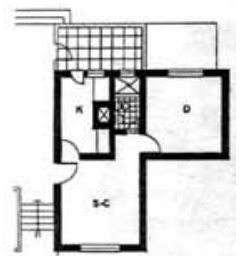

MÓDULO 2

Fuente: Caldas, 2015

ARTÍCULO: Transferencia de la idea urbana de ciudad-jardín y apropiación del modelo construido de la "Unidad Vecinal" en Lima/Patricia Caldas Torres
1965

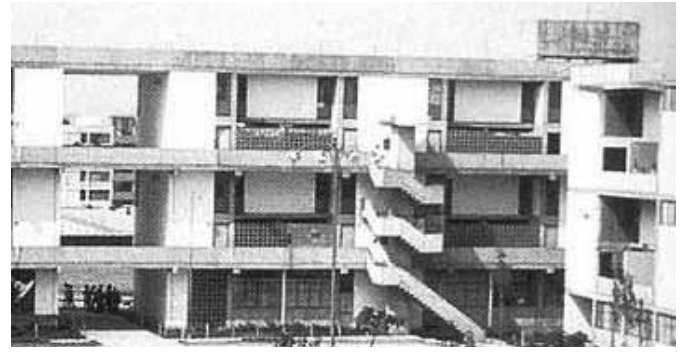

2015

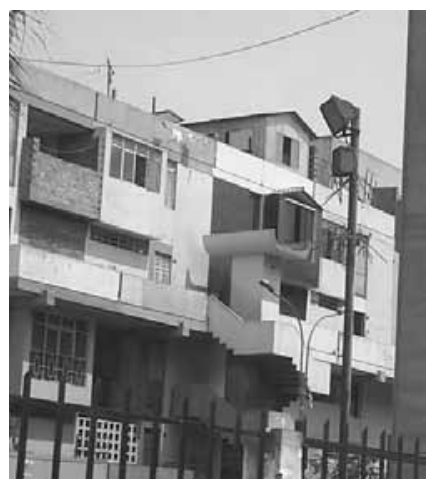

2010

2010 triplex
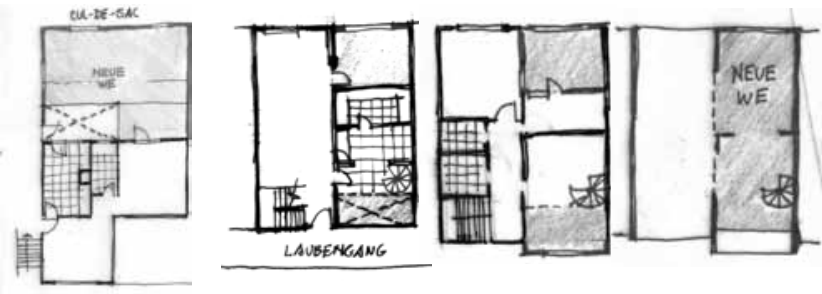

revista invi 31(87): 87-113, agosto de 2016101 


\section{PATRON DE LA FAMILIA EXTENDIDA EN EDIFICIO-BARRA}

\begin{tabular}{|c|c|c|}
\hline Año & UV3 & UV Matute \\
\hline 1949 & Padres + 1 hijo. Área: $54 \mathrm{~m} 2$ & \\
\hline 1960 & Padres + 2 hijos. Área: 70m2 & \\
\hline 1965 & Padres + 3 hijos. Área: $74 m 2$ & Padres + 1 hijo. Área: $100 \mathrm{~m} 2$ \\
\hline 1975 & $\begin{array}{l}\text { Padres }+2 \text { hijos adultos }+1 \text { hijo adulto con pareja. } \\
\text { Área: } 82 \mathrm{~m} 2\end{array}$ & Padres + 1 hijo + 1 espacio de trabajo. Área: $115 \mathrm{~m} 2$ \\
\hline 1980 & $\begin{array}{l}\text { Padres }+1 \text { hijo adulto }+1 \text { nieto }+1 \text { inquilino (pareja con } \\
1 \text { hijo). Área: } 115 \mathrm{~m} 2\end{array}$ & Padres +3 hijos +1 espacio de trabajo. Área: $130 \mathrm{~m} 2$ \\
\hline 1990 & $\begin{array}{l}\text { Padres }+1 \text { hijo adulto }+1 \text { nieto }+1 \text { inquilino (pareja con } \\
1 \text { hijo). Área: } 115 \mathrm{~m} 2\end{array}$ & $\begin{array}{l}\text { Padres }+1 \text { hijo adulto con pareja }+1 \text { hijo adulto. Área: } \\
145 \mathrm{~m} 2\end{array}$ \\
\hline 2010 & & $\begin{array}{l}\text { Padres }+1 \text { hijo adulto }+1 \text { hijo adulto con pareja }+1 \\
\text { nieto }+1 \text { espacio de trabajo. Área: } 160 \mathrm{~m} 2\end{array}$ \\
\hline
\end{tabular}

Fuente: Caldas, 2015, p. 166-167.

\section{Hacia una tipología de los cambios informales}

Se propone la siguiente tipología de cambios informales, según la figura 4: a) modificaciones constructivas de la vivienda, b) cambios en el equipamiento comunal y c) cambios del espacio público.

a) Las modificaciones constructivas de las viviendas han introducido diferenciaciones y cualidades topológicas. Los bloques crecen en el tiempo debido al crecimiento familiar a través de pequeñas intervenciones individuales en forma de extensiones horizontales, a un lado o a ambos lados del departamento, según las características del diseño, o en otras circunstancias a través de extensiones verticales

El tipo con más cambios debido al predominante crecimiento vertical es la casa en serie de UV Matute (90\% de viviendas transformadas), con extensiones sobre el retiro no tan frecuentes (15\%), sino más bien hacia los patios interiores. Por las adiciones, este tipo llega a triplicar su área original. En segundo lugar tenemos los bloques con chalets de la UV3, donde son frecuentes tanto las ampliaciones horizontales compactas del primer piso como las adiciones verticales sobre las azoteas 
de las viviendas ( $88 \%$ de bloques transformados y en ellos 90\% de viviendas ampliadas), llegando a incrementar su área entre 20-40\%. En tercer lugar están los edificios-barra con dúplex de UV Matute donde son frecuentes las adiciones del primer piso y predomina el crecimiento de los departamentos sobre espacios de doble altura (terrazas o patios-lavandería) que fungen como área libre interna disponible (100\% de bloques transformados y en ellos $75 \%$ de departamentos ampliados). Este tipo llega a incrementar su área original en más del $30 \%$. En cuarto lugar tenemos los edificios-barra pareados de la UV3, cuyo crecimiento, que se caracteriza por las adiciones del primer piso hacia la calle cul-de-sac, ha conseguido a veces duplicar el área original del departamento (100\% de los bloques modificados y en ellos 30\% de departamentos ampliados).

En los procesos de ampliación, la imagen colectiva de los bloques hacia el frente posterior resulta opacada por el carácter individual de la apropiación de la vivienda. Las adiciones informales han reforzado esta diferenciación sobre todo en la UV3, lo cual es un signo del cierto carácter diferenciado de la estructura espacial del modelo serial importado. De otro lado, las extensiones de viviendas para conformar nuevos ingresos individuales en frentes que no contaban con dichos accesos han generado una nueva situación que convierte, por ejemplo, el espacio cul-de-sac en un espacio mucho más dinámico para el peatón que el planificado originalmente para el auto.

b) Los cambios del equipamiento comunal posibilitaron nuevas facilidades comunales tanto en los centros urbanos de las UVs como en los bloques de vivienda por iniciativa colectiva o individual. En la UV Matute éstas aparecieron por iniciativa individual tanto en casas en serie como en espacios residuales del barrio o en edificios-barra (kindergarten, tiendas, talleres, centro de salud, puesto policial, etc.). En la UV3 destacan los equipamientos comunales nuevos por iniciativa colectiva (kindergarten del barrio en edificio-corredor, locales para club deportivo, asociación de jubilados, comedor popular y consultorio médico). También se consiguieron nuevas unidades de vivienda sobre las tiendas de la UV3 por iniciativa de los propios comerciantes, algunos de ellos residentes en el barrio.

c) Los cambios del espacio público en la UV Matute, en la zona de las casas en serie, han generado una metamorfosis, ya que las calles ajardinadas desaparecieron debido a que $90 \%$ de las casas presentan cercos que moldean calles estrechas con mayor proximidad entre las nuevas zonas de ingreso de las viviendas. Entre los edificios-barra con dúplex se configuraron pasajes peatonales, la estructura espacial de los patios conformados por este tipo de edificios muestra mayor flexibilidad para los cambios, se conserva la forma de los patios y las ampliaciones ocupan pequeñas áreas ajardinadas próximas al bloque. 
FIGURA 4. CAMBIOS EN UV3.

1949

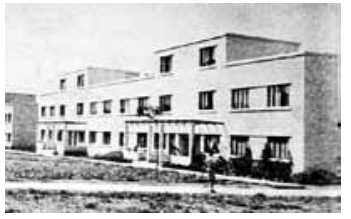

\section{BLOQUES CON CHALETS}
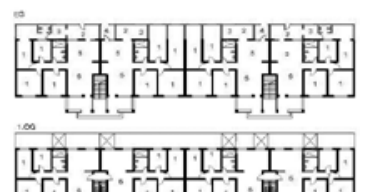

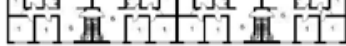

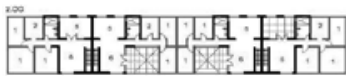

EQUIPAMIENTO COMUNAL: KINDERGARTEN ADOSADO A BLOQUE-CORREDOR.

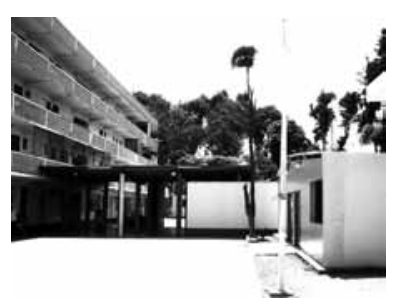

Fuente: Caldas, 2015, pp. 120-151 y fotos de la autora, 2015.
En la UV3 hay una transformación radical de su estructura espacial en la zona de los edificiosbarra, pues las calles cul-de-sac fueron moldeadas por las extensiones del primer piso como pasajes semi-públicos similares a la "quinta". Esta tipología local, común en barrios de clase media, consiste en un pasaje o patio a través del cual se accede a varias unidades de vivienda de máximo dos pisos. El pasaje o patio suele ser visto desde la calle exterior a través de una portada. En los espacios cul-desacs transformados, se logra con las ampliaciones mayor cerramiento y diferenciación del espacio. Se yuxtapone el patrón local de la "quinta" al patrón serial de los edificio-barra mediante la conformación de un pasaje central, una plaza casi circular en un extremo del pasaje y corredores de acceso a los ingresos comunes del edificio-barra existente. De esta manera, los residentes han hecho de los cul-de-sac lugares representativos de una experiencia urbana colectiva.

Los jardines públicos entre los bloques de chalets presentan más intervenciones individuales (taller, jardín privado, tienda al aire libre, garaje) que colectivas (jardín colectivo). Estos jardines públicos fueron subdivididos entre los vecinos, así las familias del primer piso asumen el cuidado de los jardines del frente delantero y las del segundo piso de aquellos jardines del frente posterior. Los límites 
entre estas áreas son muchas veces sutiles (arbustos, cercos bajos) y en otros casos más marcados (cercos altos de madera o reja). En la zona de los edificios-barra se mantiene la imagen colectiva de los jardines pues los vecinos se organizan cada 8 familias (por la caja de escalera común) para cuidarlos. Los límites son también sutiles, ya que pocas veces surge un jardín privado en medio de un jardín colectivo.

\section{Tipos de edificio-barra con crecimiento progresivo}

Se han identificado fases de la evolución tipológica de edificios-barra y "bloques con chalets" que denotan formas innovadoras de vivienda colectiva con crecimiento progresivo (figura 5) ${ }^{38}$.

Fases de crecimiento de edificios-barra pareados (UV3): en este tipo de edificio hubo primero una fase de adaptación para conseguir una cocina de trabajo y un comedor en vez de la kitchenettecomedor original. Luego se inició la primera fase de ampliación en el primer piso, hacia la calle culde-sac, con el techado de los patios posteriores y

38 Las casas en serie (UV Matute), que se transformaron generalmente en multifamiliares para el clan familiar, no se muestran en este estudio, así como tampoco el crecimiento del edificio con corredor (UV3). la delimitación de áreas ajardinadas próximas a las viviendas. En la segunda fase de crecimiento se consiguieron unidades espaciales adosadas a los frentes laterales del bloque y hacia la calle culde-sac. En la tercera fase se inició el crecimiento vertical de los edificios-barra. En una cuarta fase se consolida la diversificación de usos en los bloques de vivienda que da lugar al "bloque saturado", donde es posible encontrar en un mismo bloque departamentos, cuartos de alquiler, tiendas, negocios, talleres e incluso facilidades comunales. Se identifican claramente nuevas unidades de vivienda adosadas al bloque original en el primer piso y en los techos, por efecto del patrón de la familia extendida. El proceso de ampliación se detiene. En un par de edificios-barra se observó que el departamento del segundo piso crece sobre la ampliación compacta del primer piso.

Fases de crecimiento de las "casas con 2 viviendas de altos sobre 2 de bajos" (UV3): en la primera fase se techaron los patios posteriores y se delimitaron los jardines próximos a las viviendas a través de cercos. Aparecen las primeras extensiones en el primer piso y azotea. En la segunda fase se construyeron habitaciones en las azoteas individuales y se consiguieron departamentos independientes en el primer piso, en los frentes laterales. 
Las ampliaciones del primer piso y de las azoteas se dieron fácilmente gracias a los dos frentes libres del bloque, a la escalera de acceso independiente a las viviendas de altos y a que ya existía en el tercer piso un cuarto con azotea, al cual se le adosan nuevas habitaciones para conseguir a veces pequeños departamentos con nueva azotea o terraza.

\section{Fases de crecimiento de edificios-barra con dúplex} de la UV Matute: en la primera fase se delimitaron los pequeños jardines próximos a las viviendas del primer piso a través de cercos, sin alterar la delimitación de la vereda peatonal. En la segunda fase se iniciaron las ampliaciones horizontales del primer piso, primero frontales y luego laterales, consiguiendo nuevos ingresos a la vivienda en la parte posterior. En la segunda fase se ampliaron los departamentos de los pisos superiores sobre las terrazas de doble altura de los departamentos y el edificio-barra creció verticalmente, consiguiendo en la tercera fase algunos departamentos con acceso interior desde el interior de la vivienda. Este tipo de edificio es el que muestra ser mucho más elástico en procesos de adaptación. Las características del diseño y los espacios abiertos de doble altura permitieron la construcción por etapas prácticamente sin alterar la forma total del volumen. 
FIGURA 5. FASES DE CRECIMIENTO DE LOS BLOQUES DE VIVIENDA.

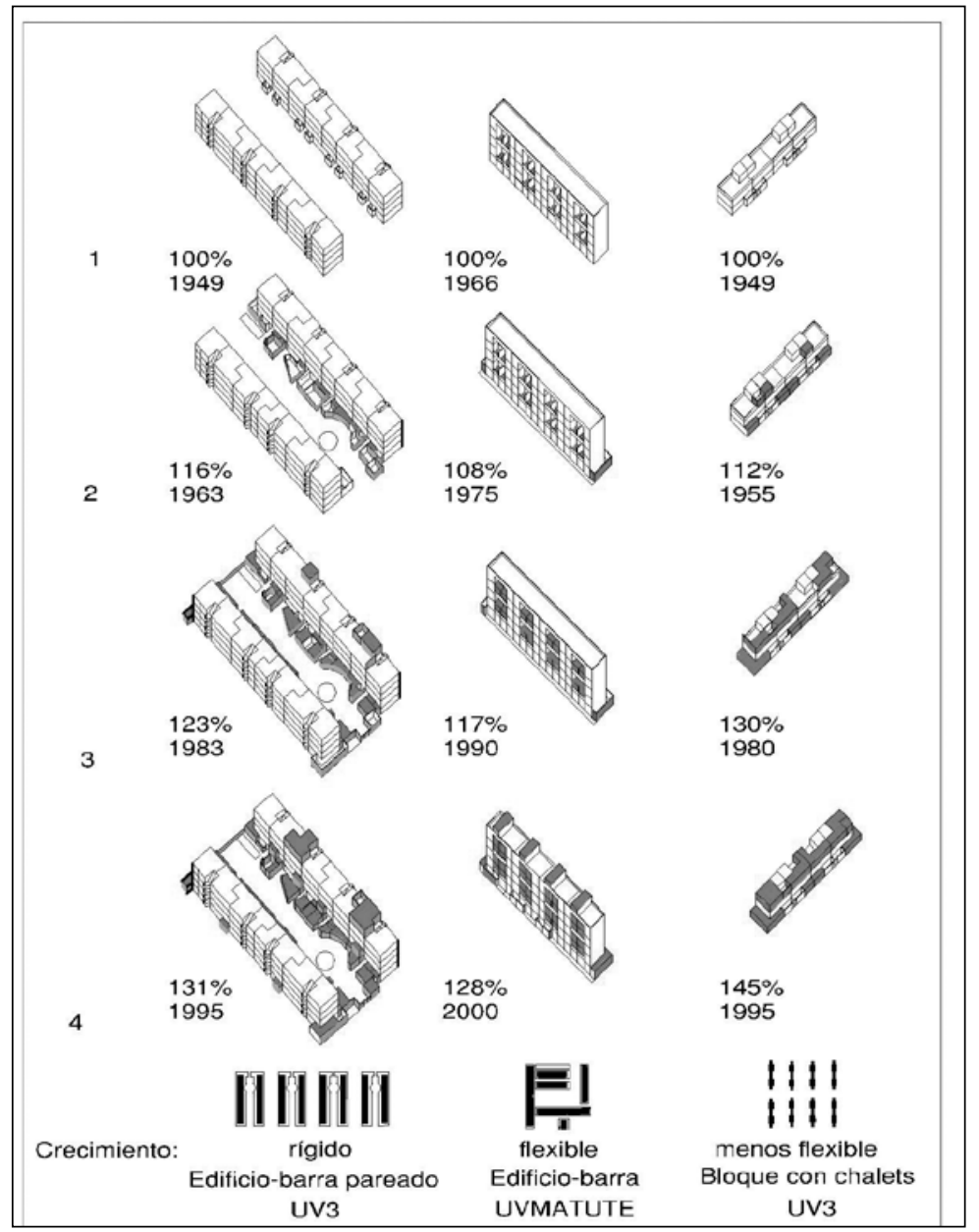

Fuente: Caldas, 2015, p. 128-145. 


\section{Transformación de la vivienda, el espacio público e imaginarios colectivos}

A nivel de la esfera privada hay estrategias de los residentes para lograr cierta independencia en la vivienda de la familia extendida. Los ingresos nuevos facilitan esta independencia para la segunda generación. Asímismo, el uso compartido de la sala, comedor y a veces de la cocina del departamento original para la gran familia resulta de gran ayuda ante la necesidad de espacio. Las ampliaciones de los últimos pisos generalmente consideran una azotea, que es un elemento local, especie de patio multiuso en el techo de la vivienda.

En las ampliaciones sobre el techo común del edificio-barra pareado (UV3), las adiciones repiten la estructura racional de la vivienda existente y la distribución se adecúa a las necesidades de cada familia. En las ampliaciones del primer piso se presenta una variedad de formas, desde la vivienda racional compacta, pasando por soluciones locales como la casa-patio, casa-jardín, hasta los cuartos accesibles por corredor.

Sobre todo las plazuelas circulares moldeadas en las calles cul-de-sac (UV3) por los habitantes fueron marcadas por ellos con elementos como piletas e imágenes religiosas como una manera de diferenciar su espacio del resto (figura 6). Las formas de

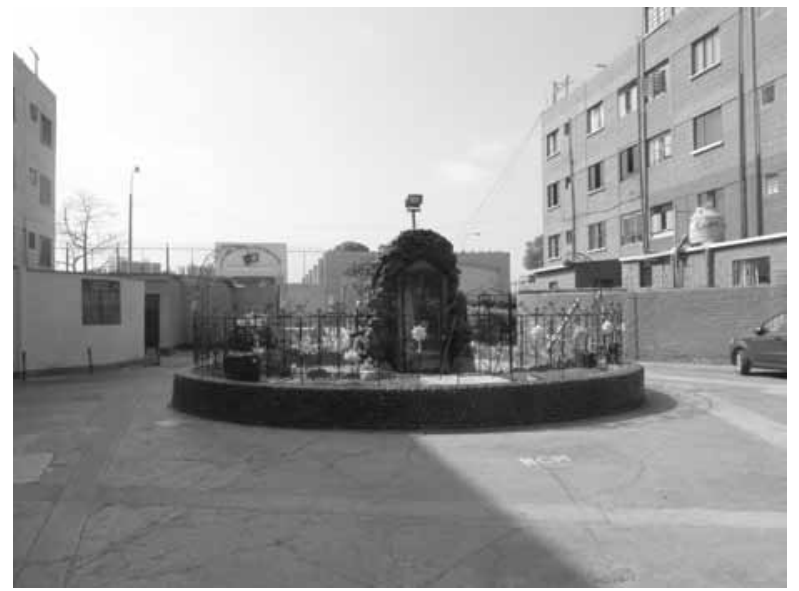

Foto: UV3; Caldas, 2015.

uso del espacio exterior reflejan la creatividad de los residentes: taller de danza, lugar de encuentro de vecinos, jardines con piscinas inflables en verano, amplios descansos en las escaleras comunes de los edificios-barra usadas a veces para grill, etc.

Las celebraciones muestran la identificación de los habitantes con sus barrios. La UV3 tiene su celebración de aniversario frente a la capilla del barrio y también festividades religiosas. En la UV Matute destacan las celebraciones de carácter religioso en la segunda etapa. La religiosidad forma parte de la cultura urbana limeña, en tal medida que no fueron los colegios de educación primaria el elemento 
esencial de cohesión social en las UVs, según la teoría del neighbourhood-unit, sino más bien las capillas. Si sumamos a esto el hecho de que los primeros párrocos trabajaron en estos barrios por más de una década y su campo de acción no se remitió al barrio -se emprendieron también programas de ayuda social para grupos más necesitados de barrios vecinos, muchos de ellos de origen informal-, podemos comprender la labor de la iglesia en el apoyo a la iniciativa de los habitantes para mejorar la calidad de vida en el barrio.

Las alteraciones del espacio público trazan nuevos dominios individuales y colectivos. Una especie de "espacio público compartido" es una constante en los jardines públicos de ambas UVs (figura 7). Las sutiles diferencias entre lo público y lo privado generan nuevas experiencias de lo público cuando el espacio urbano contiene espacios de la esfera privada (taller, tienda-terraza privada, jardín privado, etc.).

\section{Negociación comunitaria y patrones de organización generados por la apropiación}

La apropiación de las UVs ha generado sus reglas de gobernabilidad vecinal, donde existen estrategias colectivas e individuales para tomar decisiones sobre quién, qué y dónde ampliar. En el caso de la UV3, los vecinos fueron conscientes de que su barrio era un experimento urbano. A diferencia de la UV Matute, que no contó con el respaldo del Estado, la UV3 recibió apoyo de la CNV ${ }^{39}$ que fomentó acciones participativas en la administración del barrio para el mantenimiento de su infraestructura y ayuda social a sus residentes. Este respaldo estatal, que duró más de 15 años, dejó huella en sus patrones de organización ${ }^{40}$. Si bien hay ciertos problemas para llegar a acuerdos, las reglas para realizar ampliaciones son claras y existen menos conflictos que en la UV Matute.

En los bloques con chalets (UV3), los vecinos tienen cierta libertad para ampliar sus viviendas, cómo y cuándo deseen. Los problemas se generan por la desigualdad de oportunidades en las ampliaciones, ya que mientras las familias del primer piso tienen la posibilidad de conseguir un departamento independiente, las del piso superior no consiguen este tipo de ampliaciones debido a las características del diseño.

En los edificios-barra pareados (UV3) existe cierta libertad en las ampliaciones del primer piso, incluso los vecinos llegan a negociar la ocupación colectiva del espacio público para conseguir garajes de

\footnotetext{
39 CNV (Corporación Nacional de la Vivienda).

40 Diario "Unidad" (UV3), edición especial por su 50 aniversario, noviembre de 1999, editado por un vecino del barrio.
} 


\section{FIGURA 7. TIENDA EN ÁREA VERDE PÚBLICA}

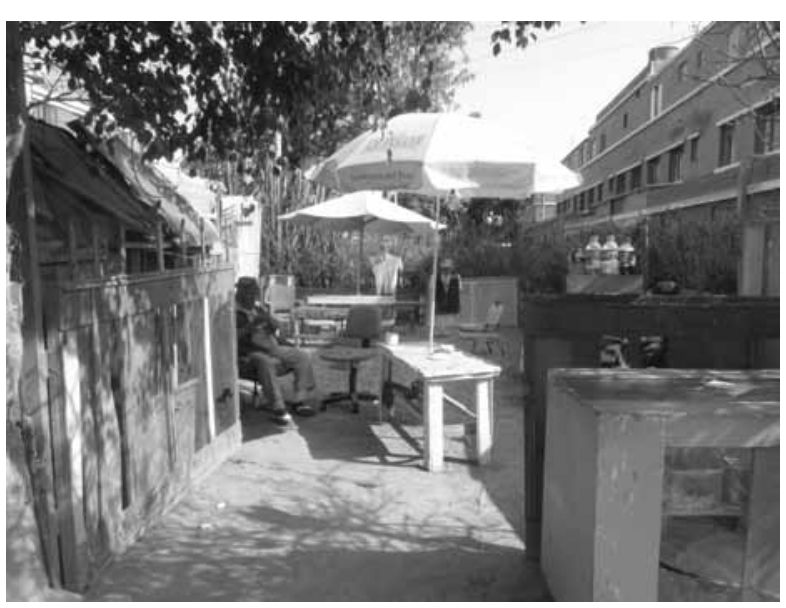

Foto: UV3; Caldas, 2015.

alquiler. La situación es distinta para las ampliaciones en la azotea común del edificio, pues aquí la familia interesada en ampliar debe negociar con todos los residentes del bloque y ofrecerles mejoras en la seguridad del edificio y mantenimiento de jardines públicos próximos para poder conseguir la aprobación.

Los habitantes de las UVs son actores sociales multifacéticos en procesos de apropiación y se organizan a través de grupos de base, vecindarios y a nivel de barrio. En la UV3 sus estrategias espaciales tienen efecto en la provisión de espacio en la vivienda existente, en su modernización y en la configuración de nuevos espacios exteriores de interacción social. Sus tácticas sociales tienen efecto en la vida comunitaria y son: participación en la administración del barrio ${ }^{41}$, organización de actividades culturales-religiosas, edición del diario barrial "Unidad" (hasta 1999), actividades para jubilados, jóvenes y madres, así como ayuda social (comedor popular y consultorio médico). Sus estrategias económicas se logran generalmente por financiamiento auto-gestionado y tienen efecto en la provisión de facilidades comunales y en asegurarse algún ingreso adicional mediante la fundación de algún negocio.

Los arquitectos de la municipalidad de Lima ven las ampliaciones como algo negativo para la apariencia física de los barrios, pero son conscientes de que los habitantes están protegidos jurídicamente, es decir tienen derecho legal de conseguir su espacio de vivienda y de trabajo para lograr su sobrevivencia. El hecho de que las ampliaciones respondan a una necesidad social ha facilitado la negociación entre residentes y autoridades locales sobre quién, dónde y qué se amplía. Más aún, algunos propietarios del primer piso han iniciado hace poco la formalización de las ampliaciones

41 En la UV3 tuvó un papel central en la organización vecinal la "Cooperativa de Servicios" (1967-78) fundada por un grupo de residentes policías. 
de sus viviendas ${ }^{42}$ y se vienen ejecutando algunos programas participativos para el mejoramiento de áreas verdes e infraestructura de los edificios.

\section{La "otra modernidad": hacia un urbanismo bottom-up}

Los resultados del estudio demuestran que el modelo importado de barrio con bloques abiertos sólo puede ser entendido en su relación con la identidad de sus habitantes y sus prácticas de apropiación. De la combinación entre una ciudad planificada (estática) y otra informal (dinámica) surge la "otra modernidad", capaz de guiar el crecimiento y desarrollo de barrios de un grupo social de clase media-baja. La "otra modernidad" se basa en la diferenciación de necesidades, acoge al patrón de la familia extendida, hace posible la construcción del lugar a través de la configuración de nuevos espacios de interacción social, con diversas categorías entre lo público y lo privado, y fomenta la provisión de espacios de vivienda y facilidades comunales en la estructura existente. Esto refuerza el sentido de comunidad y, sumado a la capacidad de este grupo social para reconocer la ampliación de la vivienda colectiva, abre posibilidades para un urbanismo incremental y soluciones de diseño

42 Según entrevista a dirigente (UV3). del "multifamiliar que crece" apartadas del diseño estandarizado.

El estudio de la "ciudad cotidiana" con sus "procesos de vida", desde una perspectiva bottom-up, pone de manifiesto que este grupo social recrea todo el tiempo su entorno construido de acuerdo a sus necesidades, según sus tácticas individuales y colectivas y mecanismos de organización. Esto abre nuevas perspectivas para los planificadores, para entender la naturaleza de la ciudad, buscar nuevos enfoques de un planeamiento urbano más flexible, y puede ser considerado para políticas de vivienda social con participación ciudadana, donde la planificación y la arquitectura sean son sólo el primer paso de un proceso y ayuden a anticiparse a situaciones de cambio.

\section{Bibliografía}

ABERCROMBIE, Patric y FORSHAW, J.H. The great London plan. Londres, Macmillan. 1943.

ANÓNIMO. Denby: Lo que ha realizado la arquitectura británica en años anteriores. Revista El Arquitecto Peruano. Junio 1944.

BOUDON, Philippe. Die Siedlung Pessac - 40 Jahre wohnen à Le Corbusier. Sozio-architektonische Studie. Gütersloh, Bertelsmann Fachverlag. 1971.

CALDAS, Patricia. Die andere Moderne. Informelle Veränderungsprozesse in staatlich geplanten Siedlungen in Lima, 1938-1971. [En línea]. 
Alemania, Hafen City Universität. 2015. Tesis doctoral. Disponible en: http://edoc.sub.uni-hamburg.de/hcu/volltexte/2015/199/.

CALDERÓN, Julio. La ciudad ilegal, Lima en el siglo XX. Lima, Fondo Editorial de la Facultad de Ciencias Sociales de la UNMSM. 2005. Serie Tesis.

--- Las ideas urbanas en el Perú. Lima, CENCA. 1990.

CASTELLS, Manuel. Desarrollo y dependencia en el proceso de urbanización en Latinoamérica. En: CASTELLS, Manuel. La cuestión urbana. México, Siglo XXI. 1974.

CóRDOVA, Adolfo. La vivienda en el Perú. Lima, Comisión para la Reforma Agraria y la Vivienda. 1957.

DELGAD0, Carlos. La Unidad Vecinal No3 y Matute: Estudio social comparativo referido a los problemas de planeamiento físico. Lima, Oficina de Planeamiento Sectorial de la Vivienda. 1966.

FRANC0, Carlos. Exploraciones en otra modernidad. De la migración a la plebe urbana. En: URBANO, Henrique, comp. Modernidad en los Andes. Cusco, Centro de Estudios Andinos Bartolomé de las Casas. 1990. p. 189-228.

FLORES, Francisco. Urbanismo y vivienda. Lima, Oficina Nacional de Planeamiento Urbano. 1967.

GARCÍA-HUIDOBRO, Fernando; TORRES, Diego y TUGAS, Nicolás, El tiempo construye: el proyecto experimental PREVI: génesis y desenlace: Barcelona, G. Gili. 2008.

HARDOY, Jorge. Theory and practice of urban planning in Europe, 1850-1930: Its transfer to Latin
America. En: MORSE, Richard, ed. y HARDOY, Jorge, ed. Rethinking the Latin American city. Washington D.C., W. Wilson Center Press, J. Hopkins University Press. 1992. p. 20-49.

HOFER, Andreas. Karl Brunner und der europäische Städtebau in Lateinamerika. Münster, LIT Verlag. 2010.

HOWARD, Ebenezer. Garden cities of to-morrow. Londres, Faber and Faber Ltd. 1946.

LEFÈBVRE, Henri. Die Revolution der Städte. Frankfurt am Main, Hain. 1990.

LINDÓN, Alicia. Diálogo con Néstor García Canclini. ¿Qué son los imaginarios y cómo actúan en la ciudad? Revista Eure. 33(99): 89-99, agosto 2007. DOI 10.4067/S0250-71612007000200008.

LOPEZ SORIA, José Ignacio. Cultura e ideología en el Perú. Casa de las Américas. 20(119): 78-87, 1980.

MATOS MAR, José. Las barriadas de Lima. 2a ed. Lima, Instituto de Estudios Peruanos. 1977.

MC GUIRK, Justin. Radical cities: across Latin America in search of a new architecture. Londres, Verso. 2014.

PETEREK, Michael. Wohnung, Siedlung, Stadt. Paradigmen der Moderne 1910-1950. Berlin, Gebr. Mann Verlag. 2000. Tesis doctoral, Universidad de Karlsruhe.

PINTOS, Juan Luis. Los imaginarios sociales: la nueva construcción de la realidad social. Maliaño, Editorial Sal Térrea. 1995. 
SASSEN, Saskia. The informal economy: between new developments and old regulations. The Yale Law Journal. 103(8): 2289-2304, Junio 1994. DOI $10.2307 / 797048$.

SEGRE, Roberto. Tres décadas de reflexiones sobre el hábitat latinoamericano. Colombia, Universidad Nacional de Colombia. 2005.

SILVA, Katharina Kirsch-Soriano da. Wohnen im Wandel. Mutationen städtischer Siedlungsstrukturen in Recife/ Brasilien. Alemania, LIT Verlag. 2010. Serie Stadt- und Raumplanung.

SILVA TELLEZ, Armando. Imaginarios urbanos. Bogotá, Arango. 2006.

WARD, Stephen, ed. The garden city. Past, present and future. Londres, E\&F SPON. 1992. 